
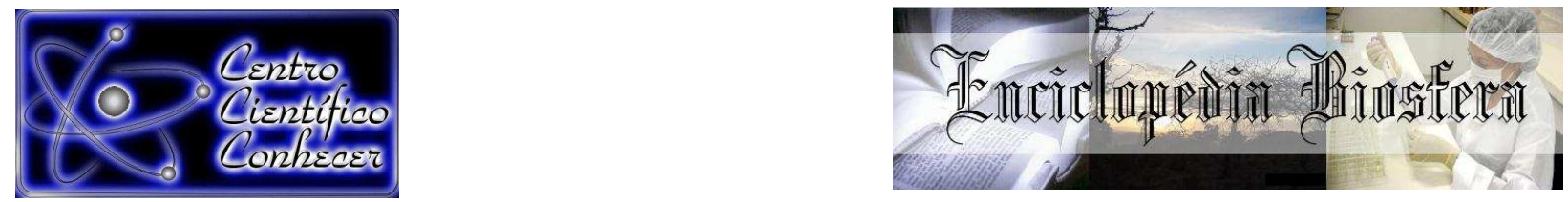

\title{
ANÁLISE MICROBIOLÓGICA DE SASHIMIS A BASE DE SALMÃO, COMERCIALIZADOS NA CIDADE DE MARINGÁ-PR
}

Fernanda Braghini ${ }^{1}$, Eduardo Gauze Alexandrino ${ }^{2}$, Fernanda Paini Leite ${ }^{3}$, Ernesto Guilherme Kemmelmeier ${ }^{4}$, José Eduardo Gonçalves ${ }^{5}$

${ }^{1}$ Mestranda do Programa de Mestrado em Promoção da Saúde do Centro Universitário de Maringá - UniCesumar - Maringá - Pr, Brasil.

(fernanda.braghini@hotmail.com).

${ }^{2}$ Mestrando do Programa de Mestrado em Promoção da Saúde do Centro Universitário de Maringá - UniCesumar - Maringá - Pr, Brasil.

${ }^{3}$ Mestranda do Programa de Mestrado em Promoção da Saúde do Centro Universitário de Maringá - UniCesumar - Maringá - Pr, Brasil.

${ }^{4}$ Professor Mestre em Análises Clínicas do curso de Biomedicina do Centro Universitário de Maringá - UniCesumar - Maringá - Pr, Brasil

${ }^{5}$ Prof. Doutor do Programa de Mestrado em Promoção da Saúde e do Programa de Mestrado em Tecnologias Limpas do Centro Universitário de Maringá - UniCesumar - Maringá - Pr, Brasil

Recebido em: 08/09/2015 - Aprovado em: 14/11/2015 - Publicado em: 01/12/2015 DOI: http://dx.doi.org/10.18677/Enciclopedia_Biosfera_2015_034

\begin{abstract}
RESUMO
O consumo de pescados, principalmente "in natura" aumentou na última década e sabe-se que a qualidade do peixe fresco pode ser influenciada por diversos fatores, mas principalmente pelos hábitos de higiene dos manipuladores de alimentos e do ambiente de trabalho. Logo, objetivou-se analisar a qualidade microbiológica do sashimi a base de salmão comercializado nos restaurantes de Maringá-PR, pois o alimento não passa por nenhum tipo de tratamento ou processamento antes do consumo, favorecendo 0 crescimento de micro-organismos potencialmente patogênicos para o desenvolvimento de gastroenterites. Para isso, realizou-se uma análise microbiológica quantitativa de 15 amostras de cinco restaurantes diferentes para identificar a presença de Salmonella spp., Coliformes Totais, Coliformes Termotolerantes e Staphylococcus aureus. Os resultados mostraram que 53,33\% das amostras analisadas deram positivos para Coliformes Termotolerantes, $100 \%$ para Coliformes Totais e nenhuma amostra apresentou contaminação por Staphylococcus aureus. Observando os resultados obtidos, nota-se um maior grau de contaminação nos restaurantes R1, R3 e R5, pois a presença de Salmonella spp. foi detectada em $20 \%$ das amostras, tornando-as inaceitáveis para o consumo. A partir desses resultados, vale ressaltar que a determinação da presença ou ausência dos micro-organismos analisados refletem diretamente nas condições higiênicas e sanitárias dos manipuladores de alimentos e de seu ambiente de trabalho.
\end{abstract}

PALAVRAS-CHAVE: Gastroenterites; Manipuladores de alimentos; peixe. 


\title{
ANALYSIS OF MICROBIOLOGICAL SASHIMI THE BASIS OF SALMON, SOLD IN THE CITY OF MARINGÁ-PR.
}

\begin{abstract}
The consumption of fish, especially "in natura" increased greatly in recent years and it is known that the quality of fresh fish can be influenced by several factors, but mainly by the hygiene of food handlers and their working environment. Therefore, the objective was to analyze the microbiological quality of sashimi salmon base marketed in the restaurants of Maringa-PR, because the food does not undergo any treatment or processing before consumption, favoring the growth of potentially pathogenic micro-organisms for development of gastroenteritis. Therefore, there was a quantitative microbiological analysis of 15 samples of five different restaurants to identify the presence of Salmonella spp., Total Coliforms, thermotolerant coliforms and Staphylococcus aureus. The results showed that $53.33 \%$ of the samples tested positive for coliform thermotolerant, $100 \%$ Total Coliform and no samples showed contamination by Staphylococcus aureus. Observing the results obtained, there is a greater degree of contamination in restaurants R1, R3 and R5 as the presence of Salmonella spp. It was detected in $20 \%$ of samples, making it unacceptable for consumption. From these results, it is noteworthy that the determination of the presence or absence of the analyzed microorganisms directly reflected in the hygienic and sanitary conditions of food handlers and their working environment.
\end{abstract}

KEYWORDS: Food handlers; Gastroenteritis; fish.

\section{INTRODUÇÃO}

Na última década, tem sido observado um aumento significativo no consumo de pescados, impulsionado pela consciência e hábitos dos consumidores em procurar alimentos mais saudáveis, visando uma melhor qualidade de vida. Segundo TONIAL et al., (2010) os alimentos de origem animal, como os peixes, são ricos em aminoácidos e principalmente em ácidos graxos (ômega 3 e ômega 6), além de serem uma das principais fontes de proteínas na alimentação.

Esta demanda por pescados gerou uma grande oferta destes alimentos em estabelecimentos especializados. O hábito de ingerir pescados "in natura" é de introdução recente nos restaurantes brasileiros, com destaque para o sashimi de salmão, um exemplo da culinária tipicamente japonesa (VALLANDRO, 2010).

Sashimi pode ser definido como um alimento de origem marítima que seja consumido cru, logo, FORSYTHE (2013) demonstra que o pescado destinado a este fim deve ser fresco e conservado sob refrigeração, com o propósito de controlar 0 desenvolvimento microbiológico. De modo geral, a qualidade do peixe fresco, bem como o desenvolvimento e disseminação de micro-organismos contaminantes podem ser influenciados por diversos fatores, entre eles: acondicionamento e transporte do peixe, atividade de água, hábitat do pescado, hábitos de higiene dos manipuladores de alimentos, tempo de exposição em prateleiras e a ação de enzimas e sucos digestivos (FORSYTHE, 2013; TONDO \& BARTZ, 2014).

VALLANDRO (2010) ressalta que o consumo de sashimi pode ser considerado de alto risco à saúde e ao desenvolvimento de problemas gastrointestinais, pois o mesmo é um alimento bastante manipulado e não passa por nenhum tipo de tratamento térmico capaz de diminuir ou eliminar possíveis microorganismos patogênicos ali presentes. 
Segundo TORTORA et al. (2010), a gastroenterite é um processo patológico de origem principalmente bacteriana, localizado na mucosa do trato gastrointestinal. Para que ocorra esta infecção, o alimento ingerido deve conter quantidades suficientes de patógenos que causem evasão das defesas do organismo, tendo como resultado a multiplicação de micro-organismos e produção de toxinas capazes de provocar distúrbios intestinais. Dentre estes micro-organismos, os principais patógenos do trato-gastrointestinal são: Escherichia coli, Salmonella spp., Campylobacter spp., Vibrio parahaemolyticus, Yersinia enterocolítica, Shigella spp., Clostridium perfringens e Bacillus cereus. Esta infecção associada a alimentos é reconhecida mundialmente, sendo muito correlacionada a manipuladores de alimentos (MIRANDA \& BAIÃO, 2011; OLIVEIRA \& MARQUES, 2012; PRADO et. al., 2014).

A Agência Nacional de Vigilância Sanitária (ANVISA), do Ministério da Saúde, através da RDC $\mathrm{n} \cong 12$, de 2 de janeiro de 2001 (BRASIL, 2001), estabeleceu limites microbiológicos sanitários para alimentos destinados a consumo, definindo no Grupo 22 (Pratos prontos para o consumo), a pesquisa dos seguintes micro-organismos: Salmonella spp., Coliformes fecais, Staphylococcus aureus e Vibrio parahaemolyticus.

É evidente, pois, a importância de pesquisar a presença de micro-organismos em pratos preparados de filés de sashimi, pois os mesmos podem transmitir microorganismos patogênicos, os quais quando em alta quantidade e associados à produção de toxinas, podem desencadear problemas gastrointestinais. Esta pesquisa teve como objetivo a análise bacteriológica de sashimis a base de salmão, comercializados na cidade de Maringá-PR, quanto à incidência de microorganismos, realizando a pesquisa de Coliformes Totais, Coliformes Termotolerantes, Salmonella spp. e Staphylococcus aureus.

\section{MATERIAL E MÉTODOS}

Realizou-se análise microbiológica quantitativa de pratos preparados para viagem, com aproximadamente $200 \mathrm{~g}$ de filés de sashimi de salmão. Estes foram adquiridos anonimamente em cinco restaurantes da cidade de Maringá-PR no período de maio a agosto de 2014, coletando três amostras por restaurante, totalizando 15 amostras. As amostras foram acondicionadas separadamente em sacos estéreis e caixas isotérmicas contendo baterias de gelo e analisadas de acordo com as normativas disponíveis na Farmacopéia Brasileira (BRASIL, 2010).

As culturas para Coliformes totais, Coliformes termotolerantes, Salmonella spp. e Staphylococcus aureus foram realizadas no Laboratório de Microbiologia do Centro Universitário de Maringá, num período máximo de 12 horas a partir do momento da coleta.

Inicialmente realizou-se a preparação das amostras para as análises, de maneira estéril em câmara de fluxo laminar, na qual, primeiramente foi realizada a desinfecção da superfície externa dos sacos contendo as amostras, com álcool 70\%, antes da abertura. Com o auxílio de bisturi, espátulas e placas de Petri estéreis, os $200 \mathrm{~g}$ de sashimi foram retirados e cortados em pequenos fragmentos, formando um pool da amostra. A partir disto, foram separadas porções de $25 \mathrm{~g}$ de cada amostra. Essas porções de cada restaurante, foram inoculadas em frascos de Erlenmeyer contendo $225 \mathrm{~mL}$ de solução água peptonada $1 \%$ estéril, formando a diluição $10^{-1}$. A partir da diluição inicial, realizaram-se as diluições $10^{-2}$ e $10^{-3}$ respectivamente em tubos de ensaio. 
Para a pesquisa de Salmonella spp. a diluição $10^{-1} \mathrm{com}$ água peptonada foi previamente incubada a $36 \pm 1^{\circ} \mathrm{C}$ por 16 a 20 horas, após essa incubação, pipetouse $0,1 \mathrm{~mL}$ da diluição para tubo contendo $10 \mathrm{~mL}$ de caldo Rappaport-Vassiliadis, e $1,0 \mathrm{~mL}$ para $10 \mathrm{~mL}$ de caldo selenito-cistina, os quais foram incubados a $45 \pm 0,5^{\circ} \mathrm{C}$ por 30 horas e a $36 \pm 0,5^{\circ} \mathrm{C}$ por 24 a 30 horas respectivamente. Em seguida, os caldos foram repicados sobre a superfície de uma biplaca contendo Agar Hektoen, que foi incubada a $36 \pm 1^{\circ} \mathrm{C}$ por 24 horas.

Para teste confirmatório, as colônias suspeitas, que apresentavam coloração de verde escuro a preta, foram submetidas às provas bioquímicas. As pesquisas de Coliformes totais e Coliformes termotolerantes, foram realizadas de acordo com a metodologia do Número Mais Provável (NMP). Foram pipetadas alíquotas de $1 \mathrm{~mL}$ de cada diluição não incubada $\left(10^{-1}, 10^{-2}\right.$ e $\left.10^{-3}\right)$ e inoculadas em 3 tubos identificados contendo Lauril-Triptose, totalizando 9 tubos para todas diluições, que foram incubados a $35 \pm 1^{\circ} \mathrm{C}$ por 24 a 48 horas.

Posteriormente efetuou-se a prova confirmatória, onde os tubos que apresentaram fermentação (produção de gás) no caldo Lauril-Triptose foram repicados com auxílio de alça bacteriológica para uma série de 9 tubos com a respectiva diluição identificada em caldo Verde Brilhante (VB) e caldo Escherichia coli (EC). Os caldos foram incubados a $35 \pm 1^{\circ} \mathrm{C}$ por $24-48$ horas e $45 \pm 1^{\circ} \mathrm{C}$ por $24-48$ horas, respectivamente.

Após a incubação e feita a contagem de tubos positivos (com produção de gás), comparou-se os resultados com a Tabela de Número Mais Provável (BRASIL, 2006; BRANDÃO et al., 2012) e os limites estabelecidos $\left(10^{2} \mathrm{NMP} / \mathrm{g}\right.$ de alimento) pela ANVISA na RDC $\mathrm{n} \cong 12$, de 2 de janeiro de 2001 (BRASIL, 2001). Para análise de Staphylococcus aureus, alíquotas de $0,1 \mathrm{~mL}$ de cada diluição não incubada foram inoculadas e com o auxílio da alça de Drigalski espalhadas sobre a superfície seca do ágar Baird-Parker e posteriormente, incubadas a 36 $\pm 1^{\circ} \mathrm{C}$ por 30-48 horas.

Após a incubação, foi realizada a contagem direta das colônias típicas (negras brilhantes com anel opaco, rodeadas por um halo claro, transparente e destacado sobre a opacidade do meio) na placa de Baird-Parker. Posteriormente com auxílio da agulha bacteriológica, foram selecionadas 1 a 3 colônias suspeitas e inoculadas em caldo Brain Heart Infusion (BHI), incubando a $36 \pm 1^{\circ} \mathrm{C}$ por 24 horas. Após esta incubação, repicou-se para ágar manitol salgado. Colônias, mesmo atípicas, foram submetidas à prova da coagulase.

Os dados obtidos foram tabulados em planilhas e posteriormente analisados através de estatística descritiva e teste Exato de Fisher para verificação de associação através do Software Statistica 8.1. O nível de significância adotado foi de $5 \%$.

\section{RESULTADOS E DISCUSSÃO}

Nas 15 amostras de filé de Sashimi de Salmão coletadas em cinco restaurantes foram pesquisados micro-organismos listados na RDC 12 de 2001 (BRASIL, 2001), para pratos prontos para o consumo à base de pescados e similares crus (Sashimi).

Segundo a Agência Nacional de Vigilância Sanitária - ANVISA, do Ministério da Saúde, através da RDC $\mathrm{n} \cong$ 12, de 2 de janeiro de 2001 (BRASIL, 2001), os valores máximos permitidos por teste analisado para este tipo de alimento são: coliformes a $45^{\circ} \mathrm{C} \leq 10^{2} \mathrm{UFC} / \mathrm{g}$, Staphylococcus aureus coagulase positiva deve ser menor que $10^{3} \mathrm{NMP} / \mathrm{g}$ e ausência de Salmonella sp. em $25 \mathrm{~g}$ de amostra.

A Figura 1 mostra a prevalência da quantidade de Coliformes Totais 
encontrados nas amostras de filé de Sashimi de Salmão obtidas de restaurantes de Maringá - PR.

\section{Coliformes Totais}

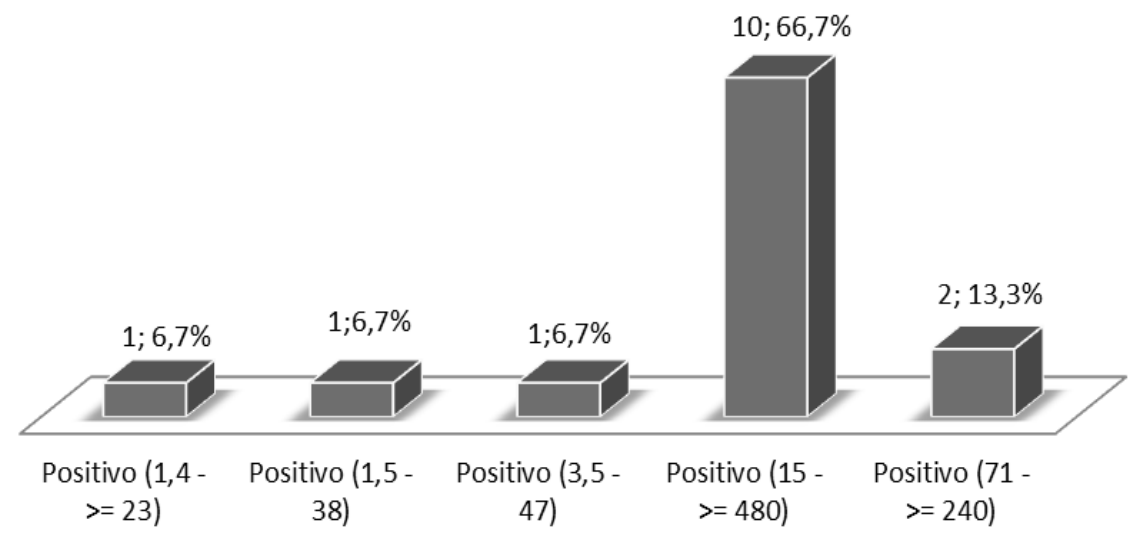

FIGURA 1 - Coliformes Totais encontrados nas 15 amostras coletadas em cinco restaurantes de Maringá PR.

Através da análise da Figura 1 observa-se que em todas as 15 amostras de filé de Sashimi de Salmão foram encontrados Coliformes Totais, variando de 1,4 à >240 NMP/g, porém a Legislação RDC 12 de 2001 não estabelece limites para pescado fresco ou refrigerado ANVISA (Brasil, 2001).

Os dados da Figura apontam que 12 amostras (80 \%) tiveram maior contaminação por Coliformes Totais. A contaminação de pescado por coliformes pode ocorrer tanto na captura e transporte, como durante o processamento efetuado nos restaurantes, sendo de grande importância a adequada higienização (VALLANDRO et al., 2011).

A Tabela 1 mostra os resultados obtidos para análise de Coliformes Termotolerantes nas 15 amostras de filé de Sashimi de salmão coletadas no período de maio a agosto de 2014 . Destas amostras, oito (53,33 \%) deram resultados positivos para Coliformes Termotolerantes, enquanto que sete amostras $(46,67 \%)$ mostrou resultados negativos para Coliformes Termotolerantes a $45^{\circ} \mathrm{C}$.

A presença de Coliformes Termotolerantes encontrados nas amostras coletadas nos restaurantes pode estar correlacionada com a presença de Escherichia coli, sendo considerada pelo Ministério da Saúde (Brasil, 2001) como a indicadora de contaminação fecal e presença de organismos patogênicos.

As amostras que apresentaram testes positivos para a presença de Coliforme Termotolerantes obtiveram os resultados entre 0,1 a $>4,7 \mathrm{NMP} / \mathrm{g}$, porém estes resultados estão de acordo com os resultados permitido pela RDC 12 de 2001 (Brasil, 2001) que deve ser inferior $10^{2} \mathrm{NMP} / \mathrm{g}$ (Tabela 1). 
TABELA 1 - Análise de coliformes termotolerantes em amostras de filé de Sashimi de Salmão coletadas em restaurantes de Maringá - PR

\begin{tabular}{|c|c|c|c|c|c|c|c|c|c|c|c|c|c|}
\hline \multirow{4}{*}{ Restaurantes } & \multicolumn{12}{|c|}{ Coliformes Termotolerantes } & \multirow{4}{*}{$p^{*}$} \\
\hline & \multirow{2}{*}{\multicolumn{2}{|c|}{ Negativo }} & \multicolumn{10}{|c|}{ Positivo (NMP/g) } & \\
\hline & & & 0,1 & $-2,3$ & 0 , & $-3,6$ & & $-4,7$ & & -12 & & -15 & \\
\hline & $\mathrm{N}$ & $\%$ & $\mathrm{~N}$ & $\%$ & $\mathrm{n}$ & $\%$ & $\mathrm{n}$ & $\%$ & $\mathrm{n}$ & $\%$ & $\mathrm{n}$ & $\%$ & \\
\hline R1 & 2 & 13,3 & 0 & & 0 & - & 0 & - & 1 & 6,7 & 0 & & \\
\hline $\mathrm{R} 2$ & 1 & 6,7 & 1 & 6,7 & 0 & - & 0 & - & 0 & - & 1 & 6,7 & \\
\hline R3 & 1 & 6,7 & 1 & 6,7 & 0 & - & 0 & - & 1 & 6,7 & 0 & - & 0,59682 \\
\hline R4 & 2 & 13,3 & 0 & - & 1 & 6,7 & 0 & - & 0 & - & 0 & - & \\
\hline R5 & 1 & 6,7 & 1 & 6,7 & 0 & - & 1 & 6,7 & 0 & - & 0 & - & \\
\hline
\end{tabular}

* Teste Exato de Fisher. Não existe associação em coliformes termotolerantes para os restaurantes analisados $(p>0,05)$

A análise dos dados contidas na Tabela 1 revela que os restaurantes R1 e R4 foram os que apresentaram o menor grau de contaminação, com resultados negativos para os Coliformes Termotolerantes em duas amostras, correspondendo a $13,33 \%$ das amostras totais para cada restaurante. Já nos restaurantes R2, R3 e R5, somente uma amostra não apresentou contaminação por Coliformes Termotolerantes (6,7\% para cada restaurante).

Apesar da variação na contaminação das amostras analisadas por Coliformes Termotolerantes, não foi possível mensurar o nível de contaminação de cada restaurante, pois não houve um grau de significância expressivo. Este fator pode ser atribuído à quantidade baixa de amostras coletadas. No estudo de MOURA FILHO \& MENDES (2007) o mesmo caso pôde ser observado na pesquisa realizada, na qual não houve diferença significativa nos níveis de contaminação entre os restaurantes.

Em pesquisa realizada na cidade de Recife (LIMA et al., 2009), notificaram valores aceitáveis em $80 \%$ (16) das amostras de Sashimi coletadas em restaurantes especializados, sendo as mesmas consideradas satisfatórias para o consumo. No trabalho relatado por MOURA FILHO \& MENDES (2007) ficou demonstrado que houve variações na presença de Coliformes Termotolerantes, e que os mesmos estavam dentro dos limites estabelecidos pela ANVISA (Brasil, 2001). Neste estudo MOURA FILHO \& MENDES (2007) relatam também que pelo menos, uma amostra de vegetal de cada restaurante investigado apresentou positividade para o NMP/g de Coliformes Termotolerantes acima do permitido.

OLIVEIRA et al. (2003) em pesquisa realizada em manipuladores de alimentos, concluíram que as condições higiênico-sanitárias do ambiente, qualidade da água, bem com a maneira de manipulação, influenciam diretamente na qualidade microbiológica do alimento. Os vegetais possuem um grau de contaminação maior do que o filé de Sashimi de Salmão consumido, logo, pode ocorrer contaminação cruzada dos vegetais utilizados para a apresentação do alimento (MOURA FILHO \& MENDES, 2007).

A análise de Salmonella sp. para as 15 amostras coletadas em cinco restaurantes (Figura 2), indicou que três (20\%) amostras, deram resultados positivos, sendo que o limite estabelecido pela ANVISA através da RDC 12 de 2001 (BRASIL, 2001) é de ausência em $25 \mathrm{~g}$ de alimento. 


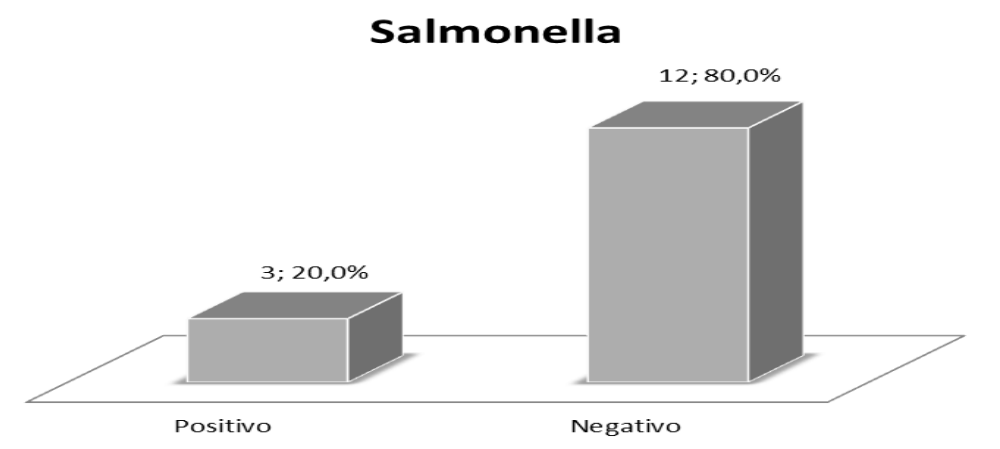

FIGURA 2 - Amostras positivas para Salmonella spp. nos restaurantes avaliados.

Estas amostras que deram o teste positivo para Salmonela spp. e desta forma foram consideradas inadequadas para o consumo, foram adquiridas de três restaurantes diferentes (R1, R3 e R5). A evidência da contaminação por Salmonela $s p$. permite concluir que os indicadores sanitários estão fora dos parâmetros aceitáveis (VALLANDRO et al., 2011).

Em relação a Salmonella sp., a maioria dos surtos tem sido relacionado ao consumo de ovos e carne de ave (CARMO et al., 2007). Pesquisas dessa bactéria em sushi e sashimi no Brasil e em outros países (EFSA, 2007) não revelaram seu isolamento, ou o fizeram em baixa frequência. Por outro lado, relatos apontam a presença de $12,2 \%$ de amostras positivas para este patógeno em pescados consumidos crus (RESENDE et al., 2009) e 18,75\% em amostras de sashimi colhidas em restaurantes (VIEIRA et al., 2007), demonstrando que existe risco de veiculação por esse tipo de alimento.

LIMA et al. (2009) relataram que de 40 amostras analisadas, nenhuma apresentou contaminação de bactérias do gênero Salmonella spp., já nos estudos realizados por MALAVOTA et al. (2009), 12,5\% (oito) das 64 amostras apresentaram resultados positivos. VIEIRA et al. (2007) também confirmaram que $25 \%$ (cinco) das amostras de sushi e $25 \%$ (cinco) das amostras de sashimi, apresentaram resultados positivos para Salmonella spp.

Para OLIVEIRA et al. (2003) a presença de uma pequena quantidade de bactérias do gênero Salmonella spp. é o suficiente para desencadear distúrbios gastrointestinais, logo, os hábitos higiênicos dos manipuladores influenciam diretamente na sanidade dos produtos. Portanto as condições de saúde dos manipuladores devem ser rigorosamente verificadas, devendo estes ser afastados do trabalho em caso de doenças, evitando assim, surtos de origem alimentar.

A análise de Staphylococcus aureus coagulase positiva apresentou níveis quantitativos consideráveis de colônias atípicas e presença de colônias típicas, no entanto, o teste de coagulase não evidenciou a presença de Estafilococos coagulase positiva nas amostras coletadas, estando estas dentro dos parâmetros estabelecidos pela Legislação Brasileira (BRASIL, 2001). Estes dados estão de acordo com os relatados na literatura (LIMA et al., 2009) descrevendo que embora a produção de enterotoxinas esteja geralmente associada ao Staphylococcus aureus coagulase e termonuclease (TNase) positivos, algumas espécies de estafilococos que não produzem nenhuma dessas enzimas também podem produzir enterotoxinas.

PRADO et al. (2014) relataram que estas cepas de estafilococos podem estar presentes nos alimentos devido à alta quantidade de Staphylococcus aureus nas mãos dos manipuladores de alimentos. VIEIRA et al., (2007) comentaram que $20 \%$ 
das amostras analisadas apresentaram valores para Staphylococcus aureus coagulase positiva além do permitido pela Legislação, já ZOLI et al. (2002) encontraram $10 \%$ de resultado positivo para Staphylococcus aureus coagulase positiva nas amostras analisadas, porém, apenas $40 \%$ destas amostras positivas, apresentaram valores acima do permitido pela Legislação vigente.

Assim, a não evidência da presença de Staphylococcus aureus coagulase positiva nas 15 amostras de filé de Sashimi de Salmão analisadas para os cinco restaurantes, pode ser justificada pela ausência de cepas não produtoras da enzima coagulase, ou também pela presença de espécies coagulase negativa que podem causar contaminação alimentar através dos manipuladores de alimentos (ANDRADE et al., 2011).

A Tabela 2 mostra o percentual de contaminação das 15 amostras analisadas para os cinco restaurantes de culinária especializada japonesa em Maringá - PR, onde três restaurantes $(60 \%)$ apresentaram uma condição higiênico-sanitária inadequada, enquanto dois restaurantes (40\%) condição higiênico-sanitária adequada, na avaliação microbiológica, de acordo com as metodologias utilizadas.

Os restaurantes R1, R3 e R5 apresentaram maior índice de contaminação, devido à presença de Salmonella spp. (Tabela 2). Nestes restaurantes a presença de Salmonella spp. foi detectada em $20 \%$ das amostras de filé de Sashimi de Salmão, tornando-as impróprias para o consumo.

TABELA 2- Percentual de contaminação segundo os restaurantes avaliados

\begin{tabular}{cccc}
\hline \multirow{2}{*}{ Restaurantes } & \multicolumn{3}{c}{ Percentual de Contaminação } \\
\cline { 2 - 4 } & $\begin{array}{c}\text { Coliformes } \\
\text { Termotolerantes }\end{array}$ & $\begin{array}{c}\text { Salmonella } \\
\text { spp. }\end{array}$ & Coliformes totais \\
\hline R1 & 33,3 & 33,3 & 100,0 \\
R2 & 66,7 & 0,0 & 100,0 \\
R3 & 66,7 & 33,3 & 100,0 \\
R4 & 33,3 & 0,0 & 100,0 \\
R5 & 66,7 & 33,3 & 100,0 \\
\hline
\end{tabular}

Quanto à presença de Coliformes Termotolerantes, apesar dos valores encontrados estarem dentro do intervalo considerado aceitável pela ANVISA, os restaurantes R2, R3 e R5 obtiveram o maior percentual de contaminação. Vale ressaltar que a determinação da presença ou ausência dos micro-organismos analisados é de extrema importância, pois tais dados refletem diretamente as condições higiênicas e sanitárias dos manipuladores de alimentos e do ambiente de trabalho.

$\mathrm{Na}$ cadeia alimentar, práticas higiênicas eficientes são necessárias em cada parte do processo, desde a produção até o consumo dos alimentos, sendo que cada etapa deste processo pode influenciar a qualidade e a segurança dos alimentos. Associado as práticas higiênicas, os cuidados com a cadeia fria de conservação de produtos perecíveis e o transporte do alimento processado são fundamentais para manter as populações bacterianas abaixo das doses infectantes para o consumidor. Nos casos dos alimentos consumidos crus, como o filé de sashimi de salmão (culinária japonesa), esses processos são ainda mais importantes e devem ser controlados pela adoção de Boas Práticas de Fabricação e fiscalizados pelas agências sanitárias. 


\section{CONCLUSÃO}

Este trabalho evidenciou a importância da análise microbiológica de alimentos à base de filés crus de sashimis, pois esse alimento não passa por nenhum tipo de tratamento e/ou processamento na hora do consumo, favorecendo o crescimento de micro-organismos.

A presença de Salmonellas spp. em três dos cinco restaurantes que comercializam filé de Sashimi, mostraram condições sanitárias insatisfatórias. Neste sentido, recomenda-se aos profissionais responsáveis pela manipulação e distribuição de produtos à base de pescado cru, medidas higiênico-sanitárias mais rigorosas através da adoção e aplicação das Boas Práticas de Fabricação, a fim de controlar os possíveis riscos potenciais à saúde do consumidor.

\section{REFERÊNCIAS}

ANDRADE, A. P. C; BORGES, M. de F.; FIGUEIREDO, E. A. T.; MACHADO, T. F.; PORTO, B. C. Boletim de pesquisa e desenvolvimento: perfil de staphylococcus coagulase positiva e negativa contaminantes de queijo coalhado. Publicado em: EMBRAPA - Empresa Brasileira de Pesquisa Agropecuária. Fortaleza, 2011. Disponível em: <http://www.cnpat.embrapa.br/download_publicacao.php?id=353> Acesso em: 21 de Abril de 2015.

BRANDÃO, M. L. L.; ROSAS, C. de O.; MEDEIROS, V. de M.; WARNKEN, M. B.; BRICIO, S. M. L.; SILVA, A. M. L.; AZEREDO, D. R. P. Comparação das técnicas do número mais provável (NMP) e de filtração em membrana na avaliação da qualidade microbiológica de água mineral natural. Revista do Instituto Adolfo Lutz. V. 71, n. 1, p. $32-39,2012$.

BRASIL, Ministério da Saúde, Agência Nacional de Vigilância Sanitária. Farmacopéia Brasileira. $5^{\mathrm{a}}$ edição, 2010. Disponível em: <http://www.anvisa.gov.br/hotsite/cd_farmacopeia/index.htm> Acesso em: 21 de Abril de 2015.

BRASIL, Ministério da Saúde, Agência Nacional de Vigilância Sanitária. Vigilância e Controle da Qualidade da Água para Consumo Humano. 2006. Disponível em: < http://bvsms.saude.gov.br/bvs/publicacoes/vigilancia_controle_qualidade_agua.pdf> Acesso em: 21 de Abril de 2015.

BRASIL, Ministério da Saúde, Agência Nacional de Vigilância Sanitária. Resolução RDC no 12, de 02 de janeiro de 2001. Disponível em:

<http://portal.anvisa.gov.br/wps/wcm/connect/a47bab8047458b909541d53fbc4c6735 /RDC_12_2001.pdf?MOD=AJPERES> Acesso em: 21 de Abril de 2015.

CARMO, G. M. I.; DIMECH, C. P. N.; ALVES, R. M. S. Vigilancia dos surtos de doencas transmitidas por alimentos, Brasil, 1999 - 2006. Revista Higiêne Alimentar., v. 21, n. 150, p. $353-354,2007$.

EFSA (European Food Safety Authority). The Community Summary Report on Trends and Sources of Zoonoses, Zoonotic Agents, Antimicrobial Resistance and ENCICLOPÉDIA BIOSFERA, Centro Científico Conhecer - Goiânia, v.11 n.22; p.3173 2015 
Foodborne Outbreaks in the European Union in 2006. EFSA J., 130 p., 2007. em: <http://www.eventosufrpe.com.br/jepex2009/cd/resumos/R0620-1.pdf>. Acesso em: 22 de abril de 2015.

FORSYTHE, Stephen J. Microbiologia da segurança dos alimentos. 2 ed. p. 104 - 107; 144-145 Porto Alegre: Artmed, 2013.

LIMA, R.M.T.; SHINOHARA, N. K. S.; SIQUEIRA, L. P.; LIMA, R. C. T.; PIRES, E.F.; XIMENES, G. N. C.; BARBOSA, V. B. Avaliação microbiológica de sushis e sashimis comercializados na cidade do Recife-PE. Pernambuco, 2009. Universidade Federal Rural do Rio de Janeiro. IX Jornada de Ensino Pesquisa e Extensão - JEPEX 2009. Recife, 2009.

MALAVOTA, L. C. M.; COSTA, J. C. B.; JARDIM, M. F.; OLIVEIRA, L. A. T.; FRANCO, R. M.; OLIVEIRA, V. M. Ocorrência de Vibrio parahaemolyticus e Salmonella spp em "sashimis" comercializaos em restaurantes no município do Rio de Janeiro. Revista Brasileira de Ciência Veterinária, v. 16, n. 2, p. 89-94, maio/ago. 2009.

MIRANDA, A. C. B.; BAIÃO, R. C. L. Avaliação nas boas práticas de fabricação de preparações à base de pescados crus em restaurantes japonês. Ciência \& Desenvolvimento - Revista Eletrônica da Fainor, v.4, n.1, p.52-61, jan./dez. 2011

MOURA FILHO, L. G. M. M.; MENDES, E. S. Enumeração e pesquisa de vibrio spp. e coliformes totais e termotolerantes em sashimis de atum e vegetais comercializados na região metropolitana do Recife, Estado de Pernambuco. Dissertação. 2007. Universidade Federal Rural de Pernambuco.

OLIVEIRA, A. M. GONÇALVES, M. O.; SHINOHARA, N. K. S.; STAMFORD, T. L. M. Manipuladores de alimentos: um fator de risco. Higiêne Alimentar, Recife, v. 17, n.114/115, p. $12-19,2003$.

OLIVEIRA, T. W. N.; MARQUES, L. F. Avaliação das condições higiênica- sanitária no preparo de sushi e sashimi de um estabelecimento comercial. Revista Semiárido de Visu - IBICT, v.2, n.1, p.194-201, 2012.

PRADO, B. G.; IWATANI, J. E.; PEREIRA, M. R.; GOLLUCKE, A. P. B.; TOLEDO, L. $P$. Pontos críticos de controle na qualidade higiênico-sanitária do preparo de sushis e sashimis no município de São Vicente, São Paulo. Segurança Alimentar e Nutricional, Campinas, 21(1):359-372, 2014.

RESENDE, A.; SOUZA, J. R.; OLIVEIRA, Y. S. Analise microbiológica de sushis e sashimis comercializados em restaurantes de Brasília no período de 2001 a 2004. Revista Higiene Alimentar, v. 23, p. 164 - 170, 2009.

TONDO, E. C.; BARTZ, S. Microbiologia e sistemas de gestão da segurança de alimentos. p. 17-22. Porto Alegre: Sulina, 2014.

TONIAL, I. B; OLIVEIRA D. F; BRAVO C. E.C; SOUZA N. E; MATSUSHITA M; VISENTAINER J.V. Caracterização Físico-Química e Perfil Lipídico do Salmão ENCICLOPÉDIA BIOSFERA, Centro Científico Conhecer - Goiânia, v.11 n.22; p.3174 2015 
(Salmo salar L.). Alimentos e Nutrição - Brazilian Journal of Food and Nutrition., v. 21, p. 93-98, 2010.

TORTORA, G. J.; FUNKE, B. R.; CASE, Christine L. Microbiologia. 10 ed. p. 710713. Porto Alegre: Artmed, 2010.

VALLANDRO, M. J.; CAMPOS, T.; PAIM, D.; CARDOSO, M.; KINDLEIN, L. Avaliação da qualidade microbiológica de sashimis a base de salmão, preparados em restaurantes especializados em culinária japonesa. Revista do Instituto Adolfo Lutz, v. 70, n.2, p. $144-150,2011$.

VALLANDRO, Marcelo J. Avaliação da qualidade microbiológica de sashimis a base de salmão, preparados em restaurantes especializados em culinária japonesa na cidade de Porto Alegre - RS. Dissertação (Mestrado em Bacteriologia), Universidade Federal do Rio Grande do Sul, 2010.

VIEIRA, R. H. S. F.; SILVA, C. M.; CARVALHO, F. C. T.; SOUZA, D. B. R.; MENEZES, F. G. R.; REIS, E. M. F. Salmonella e Staphylococcus coagulase positiva em sushi e sashimi preparados em dois restaurantes da cidade de Fortaleza, Ceara. Boletim Técnico Científico do CEPENE - ICMbio, v. 15, n. 1, p, 9-14, 2007.

ZOLI, J. A.; NEGRETE, I. R. A.; OLIVEIRA, T. C. R. M. Avaliação da contaminação por staphylococcus aureus e salmonella spp., de maionese de batata comercializada em Londrina, PR. Higiene Alimentar, Londrina, vol. 16, n. 95, p. 62 - 71, 2002. 